\title{
LA ETNOEDUCACIÓN COMO POSICIONAMIENTO POLÍTICO E IDENTITARIO DEL PUEBLO AFROECUATORIANO
}

\section{Etnoeducation as a Tool for Positioning the Identity of the Afro-Ecuadorian Community}

\section{ROCÍO VERA SANTOS*}

Fecha de recepción: 04 de agosto de 2017 - Fecha de aprobación: 11 de octubre de 2017

\section{Resumen}

La investigación se orienta a demostrar cómo la población afrodescendiente en Ecuador ha generado, desde la etnoeducación, procesos históricos de transformación epistemológica por medio de la difusión de conocimientos ancestrales como una forma de posicionamiento político e identitario.

En la primera parte, desde una perspectiva postcolonial y decolonial, se presenta los conceptos teóricos para abordar los posicionamientos políticos, epistemológicos y culturales de los líderes y lideresas afroecuatorianos involucrados en el fortalecimiento de la identidad a través de la implementación de la etnoeducación en el sistema educativo. En la segunda parte, "casa adentro", se analizan las estrategias de representación de la sociedad civil afroecuatoriana y de actores religiosos y académicos que desde 1979 de manera localizada han elaborado y difundido material etnoeducativo a fin de contrarrestar la invisibilización de los aportes del pueblo afroecuatoriano en la construcción del Estado Nación y modificar con ello la visión racista, estereotipada y homogénea que la sociedad blanco mestiza ha construido sobre ellos. La tercera parte, "casa afuera", analiza la incidencia a nivel de política pública de la incorporación de la etnoeducación afroecuatoriana en el diseño del currículo educativo nacional desde 2016. El estudio argumenta que la etnoeducación se ha constituido en una herramienta esencial para fortalecer la identidad afroecuatoriana y para confrontar el racismo estructural y la discriminación institucionalizada.

Palabras clave: Etnoeducación afroecuatoriana, conocimiento ancestral, articulaciones identitarias, políticas de representación, discriminación racial

\section{Abstract}

The research aims to demonstrate how the Afro-descendant population in Ecuador has generated historical processes of epistemological transformation through the rescue and diffusion of ancestral knowledge as form of political and identity positioning.

In the first part, from a postcolonial and decolonial perspective, theoretical concepts are presented to address the political, epistemological and cultural positions of the Afro-Ecuadorian leaders involved in the strengthening of identity through the implementation of ethno-education in the education system. The second part, "inside home," explores the strategies of representation of Afro-Ecuadorian civil, religious and academic actors, who since 1979 have developed and disseminated ethno-educational material to counteract the indifference towards, and the stereotyped view of, the Afro-Ecuadorian community. The third part "outside home" presents an overview of the journey towards inclusion of Afro-Ecuadorian ethno-education in the national curricular design in 2016. The article argues that ethno-education has become an essential tool for strengthening the identity of Afro-Ecuadorians, and that it has been used to challenge structural racism and institutionalized discrimination against the community.

Keywords: Afro-ecuadorian ethno-education, ancestral knowledge, identity articulation, politic of representation, racial discrimination

* Dra. Phil. en Sociología. Docente e investigadora científica en el Instituto de Estudios Latinoamericanos, Universidad Libre de Berlín, Berlín, Alemania. El artículo está enmarcado en su tesis doctoral. Correo-e: rocio.vera@fu-berlin.de 


\section{Introducción}

El proceso de construcción de identidades étnicas y posicionamientos epistemológicos han debido negociarse constantemente con un régimen racializado de representaciones creado desde el colonialismo y la esclavitud, en donde el africano y africana fue llamado negro y negra, y su cuerpo fue utilizado como fuerza de trabajo esclavo. Los aportes culturales, sociales y políticos de los afrodescendientes en las diferentes naciones fueron invisibilizados. Existieron, sin embargo, espacios de libertad y autonomía. La región de Esmeraldas por ejemplo, se constituyó desde el inicio de la colonia como un territorio de acogida para los cimarrones hombres y mujeres que lograban huir tanto de las minas como de las haciendas del Valle del Chota y Mira. Con la expulsión de los jesuitas en 1767 se dio el traspaso de la administración de las haciendas cañeras al gobierno colonial, ocasionando que ciertos derechos adquiridos por los esclavizados y esclavizadas no fuesen respetados, generándose una serie de rebeliones a finales de 1770. Acciones de denuncia como las llevadas a cabo por la esclavizada Martina Carrillo, permitió que se reconocieran normativas consuetudinarias establecidas en la gobernación jesuita, mediante las cuales se definía el tiempo y la carga de trabajo, así como los derechos básicos de alimentación y cuidado. De acuerdo con Chaves (2009), este reconocimiento que hizo la Real Audiencia de Quito a esta normativa se constituyó como el primer código de regulación de trabajo esclavo en la región, anterior a la emitida por la Corona española en 1789 denominada Instrucción sobre Educación, Trato y Ocupación de los Esclavos, la misma que fue suspendida en sus efectos en 1794 (Lucena, 1994).
Los africanos y sus descendientes, en la formación del Estado Nación ecuatoriano de 1830, fueron excluidos dentro del imaginario de identidad nacional blanco-mestiza. Los indígenas y afroecuatorianos eran considerados un "problema" para el desarrollo nacional. Sus acciones en pro de la libertad y la democracia fueron invisibilizadas, así como su participación en las guerras independentistas y por la manumision de la esclavitud. Estas acciones colectivas muestran, sin embargo, que los esclavizados y esclavizadas eran agentes activos que luchaban por la libertad y la igualdad. Al declararse la abolición de la esclavitud en territorio ecuatoriano quedaban pocos esclavos (Andrews, 2007, p. 76), la gran mayoría había comprado su propia libertad, o la de sus familiares, sin embargo en la práctica no gozaban de los mismos derechos ciudadanos. Es decir, existió una discriminación legal indirecta ya que a pesar de que no existieron normas que distinguiesen racialmente a los grupos sociales, su implementación generaba impactos diferenciados entre los grupos. La ciudadania estaba supeditada a la propiedad sobre tierras $u$ otros bienes inmuebles, al pago de impuestos, saber leer y escribir, o a no laborar (o incluso no haber laborado en el pasado) en ciertos oficios que implicaran servidumbre.

Tras la abolición de la esclavitud, concluida oficialmente en 1854, los amos fueron indemnizados por la pérdida de mano de obra esclava, mientras que los ex esclavizados y esclavizadas sin gozar de ningún tipo de garantía económica, política o territorial fueron sometidos al concertaje y huasipungo ${ }^{1}$. Este trabajo campesino fue modificado con la Ley de Reforma Agraria y Colonización de 1964, la cual a pesar de que terminó con el huasipungo -la última forma de explotación colonial-, no distribuyó equitativa- 
mente la tierra, y declaró tierras "ancestrales" como tierras baldías ocasionando que varios grupos de familias afroecuatorianas provenientes de asentamientos tradicionales como el Valle del Chota y Esmeraldas emigren a otras ciudades y a la capital del Ecuador, accediendo generalmente a trabajos mal remunerados y de gran esfuerzo físico.

A partir de las décadas de 1980 y 1990, en que se globaliza el multiculturalismo, las políticas de identidad y el reconocimiento a la diferencia, bajo principalmente los postulados del Convenio 169 de la OIT, la movilización del sector indígena y afroecuatoriano a la ciudad de Quito, permitió redefinir la supremacía mestiza, logrando que el Estado ecuatoriano a través de la Constitución de 1998 reconozca a los indígenas y afroecuatorianos como ciudadanos y sujetos de derechos colectivos. Por tanto, desde el aspecto legal, los indígenas fueron reconocidos como "nacionalidades indígenas", y los afroecuatorianos como "pueblo negro o afroecuatoriano". Tras algunas décadas, estas categorías permitieron a ambos grupos generar importantes reivindicaciones, principalmente de índole territorial e identitaria.

Las reformas constitucionales, así como el mensaje que manejan las organizaciones estatales en referencia a esta población construyeron un discurso que se basa en una identidad homogénea del "pueblo afroecuatoriano", sin mayores diferencias regionales, históricas, culturales, y políticas, asumiendo que este pueblo se ubica solamente en zonas ancestrales -Provincias del Carchi, Imbabura y Esmeraldas-, es decir, territorializando a los grupos y excluyendo, por tanto, simbólica y materialmente a los afroecuatorianos que viven en las zonas urbanas, en donde actualmente se ubica el 74.4\% de la población (INEC 2010).

Este reconocimiento a las identidades étnicas no significó necesariamente una modificación en las relaciones de desigualdad social, discriminación ${ }^{2}$ y racismo estructural. Con la incorporación de la categoría étnica en los censos de población y vivienda en el 2001 y 2010 se evidenció las grandes brechas de desigualdad social entre las poblaciones afrodescendientes e indígenas frente a los blancos y mestizos con notables desventajas especialmente por tasa de pobreza ${ }^{3}$, limitado acceso a la educación superior ${ }^{4}$, y mala cobertura de acueducto y alcantarillado 5 en los hogares.

En contraposición a la idea esencialista de identidad afroecuatoriana construida desde el colonialismo y reforzada a través del discurso de las élites hegemónicas y el Estado, así como la circulación de representaciones sumamente estereotipadas y racistas hacia la población afroecuatoriana en los medios de comunicación, en los materiales educativos, así como en los discursos de la vida cotidiana, esta investigación evidencia que desde finales de la década de 1970 se han creado espacios de discusión para reescribir una historia negada, dentro de lo que el maestro Juan García 6 llamó "casa adentro" y "casa afuera", una metodología que reivindica el saber y conocimiento ancestral afroecuatoriano. Este conocimiento se posiciona como una epistemología propia, que apunta a fortalecer el proyecto intercultural ecuatoriano:

El tiempo "casa adentro" se constituye por los espacios autónomos para fortalecer lo propio, a nivel comunitario o barrial a través del saber colectivo (cultura) y el derecho a ser autónomos (política); el tiempo "casa afuera", se constituye por los espacios para compartir con los otros, (Estado y Sociedad), usando los canales de la interculturalidad que propone la nación, a fin de 
enseñar a los otros sobre la realidad afroecuatoriana (Pabón, 2011, p. 26).

La presente investigación se orienta a demostrar cómo la población afrodescendiente en Ecuador ha generado desde la propuesta de etnoeducación procesos de transformación epistemológica en el rescate y producción de conocimientos, presentándose estos como contra discursos y políticas de representación propia, en contextos aún marcados por el racismo, la exclusión y la desigualdad.

\section{Acercamiento teórico y metodológico}

Para realizar un análisis del proceso de incorporación de la etnoeducación en el currículo educativo, he considerado los aportes de Stuart Hall, (1996a) en particular el concepto de articulaciones identitarias. Utilizando esta categoría analítica se puede observar en la narrativas de los sujetos cómo estos han sido interpelados en los diferentes discursos, ubicándolos en ciertas posiciones o locaciones sociales fijas, y por otro lado, el lugar de enunciación de los sujetos dentro del discurso a través de un proceso de subjetivación, que da cuenta de un posicionamiento, es decir, de su capacidad de agencia (Hall, 1996a). Este posicionamiento se puede evidenciar a través de estrategias de representación que, por un lado, cuestionan los regímenes racializados de representación, reinvirtiendo estereotipos de lo negativo a lo positivo a través de una modificación en las relaciones de representación sumamente desiguales, estereotipadas y discriminatorias $y$, por el otro, una intervención en los discursos y estructuras a través de representaciones propias, las cuales se construyen desde un reconocimiento de experiencias y subjetivi- dades, es decir, la generación de políticas de representación, que lleven a construir nuevos sujetos, y nuevas etnicidades (Hall, 1997). En este sentido el término etnicidad:

reconoce el lugar que juega la historia, el lenguaje y la cultura en la construcción de la subjetividad y la identidad, al igual que el hecho de que todo discurso está localizado, posicionado y situado y de que todo conocimiento es contextual (Hall, 1996b. En Restrepo, Walsh \& Vich, 2010, p. 310).

Desde este posicionamiento los sujetos pueden hablar y asumir: pasado, tradición, memoria y lugar histórico. Se recurre al pasado pero este es ahora visto y tomado como una historia, como algo que tiene que ser narrado. Conociendo el pasado del que preceden, pueden los sujetos afrodescendientes descubrir y redescubrir los recursos a través de los cuales están en capacidad de posicionarse.

La vinculación con el pasado, con las tradiciones, con la memoria, es construida en la narrativa; está en la memoria colectiva que se intenta recuperar a fin de interpelar el proyecto y las formaciones discursivas hegemónicas sumamente racializadas mediante las cuales han sido imaginados los afrodescendientes, para poder con ello hablar por sí mismos (Hall, 2001). La estrategia de políticas de representación hace referencia no solo a la producción de conocimientos sino que al mismo tiempo tiene el fin de ser una práctica social y política, remite a una intervención dedicada a influir los términos en los que lo social se constituye, haciendo evidente la contingencia de las fronteras que definen a los grupos, con el objetivo de combatir las certezas simbólicas en las cuales están fundamentadas las prácticas de discriminación y racismo (Costa \& Gurza, 2006). 
En este sentido, Hall presenta una postura alternativa a las dos concepciones multiculturalistas clásicas: el multiculturalismo comunitarista y el multiculturalismo liberal. Ambas corrientes pusieron énfasis en la pertenencia cultural y en la necesidad de que el Estado preserve y estimule los vínculos entre los individuos y sus culturas, pero utilizaron argumentos distintos: los comunitaristas entendieron la comunidad basada en una precedencia ontológica, en donde cada individuo realiza un proceso de autodescubrimiento de su cultura aprendida dentro de su grupo de pertenencia. Los liberales por su parte, concibieron la cultura y sus prácticas no como algo innato o intrínseco, sino como elementos que los individuos desde sus juicios, procesos de reflexión y formación de preferencias pueden utilizarlos como referentes culturales o identitarios (Costa \& Gurza, 2006). Siguiendo a estos autores, el papel del Estado difiere según el enfoque que se adopte, así, para los comunitaristas la diversidad cultural es un bien público que debe preservar el Estado ya que los individuos forman parte de manera intrínseca de sus comunidades; mientras que los liberales consideran que el Estado debe preservar su neutralidad, es decir, al Estado no le corresponde normatizar un vínculo de los individuos con determinado grupo cultural ya que los individuos pueden en función de sus intereses y elecciones escoger su grupo cultural de pertenencia, por lo tanto, el Estado solo debe preservar los diferentes acervos culturales para que los individuos puedan recurrir a ellos como una elección personal.

Hall presenta una alternativa desde la noción de nuevas etnicidades, cuyo énfasis está en las articulaciones identitarias, en los procesos de posicionamiento de los sujetos, en donde se representa una etnicidad no coercitiva y más diversa, es decir una etnicidad que se desvincule del discurso dominante del multiculturalismo, o en asociación siempre racializada de los grupos llamados étnicos, pero que utilizan también esa vinculación racializada de la etnicidad para luchar contra el racismo y la discriminación. El posicionamiento al que se hace referencia tiene que ver con una conciencia de la experiencia de la diáspora africana y las consecuencias que esto conlleva al proceso de desestabilización, recombinación, y construcción histórica, cultural y política de nuevos sujetos.

A su vez, el concepto de Atlántico Negro propuesto por Paul Gilroy (1993), lo utilizo para hacer referencia a la creación de una cultura negra transnacional, no entendida como el resultado de una esencia, sino como un espacio glocal que los descendientes de la diáspora africana encontraron en cada nación, para intercambiar experiencias y creaciones con otras culturas negras presentes en todo el mundo. De ello, se destaca el surgimiento de marcas transatlánticas y su capacidad de adaptación y reconstrucción de elementos tradicionales y modernos. Estas prácticas culturales se han orientado históricamente a una lucha por la libertad, por la ciudadanía y por espacios autónomos en el sistema político formal de los estados en las sociedades modernas. En este sentido se entiende el Atlántico Negro como un espacio de articulación de antirracismo, en donde se postula que lo que vincula a las diversas poblaciones afrodescendientes no es necesariamente la ancestralidad africana, ni los rasgos físicos, sino las experiencias similares de opresión racista y de lucha contra la discriminación.

Considero que estas prácticas culturales de la diáspora africana constituyen proyectos que dan cuenta del accionar de los sujetos, movimientos y pueblos por intervenir y trans- 
formar los legados de la colonialidad del poder que por siglos ha posicionado a los afrodescendientes como "los últimos otros", desconociendo sus aportes políticos, económicos, epistémicos, culturales y sociales.

Aníbal Quijano (1992) introdujo el concepto de colonialidad del poder, para hacer referencia a la imposición de una clasificación étnico/racial en las poblaciones colonizadas, en base a la cual se desprende una histórica distribución desigual del poder en todos los ámbitos de la vida, tanto a nivel material como simbólico. En esta clasificación los grupos racializados ocupan diferentes posiciones sociales desventajadas, enmarcadas en la reproducción de relaciones de dominación:

Las nuevas identidades históricas producidas sobre la base de la idea de raza fueron asociadas a la naturaleza de los roles y lugares en la nueva estructura global del control del trabajo. Así ambos, elementos, raza y división del trabajo, quedaron estructuralmente asociados y reforzados mutuamente, a pesar de que ninguno de los dos era necesariamente dependiente el uno del otro para existir o para cambiar (Quijano, 2000, p. 204).

Esta forma de naturalizar y legitimar las posiciones de los sujetos en la sociedad fue, y es, el marco dentro del cual operan las otras relaciones sociales, configurándose discriminaciones sociales vistas como resultados de fenómenos naturales y no de la historia del poder (Quijano, 1992, p. 438). Esta estructura no solo sirvió para justificar la explotación y el sometimiento, sino que se extendió a otras áreas de la vida como es la producción de conocimiento. En este sentido dentro de esa matriz de poder no solo los sujetos fueron inferiorizados sino que sus conocimientos, saberes, estilos de vida, religiones, valores, prácticas políticas, modelos de desarrollo económico, fueron por siglos invisi- bilizados, ignorados y / o descalificados. Solo la cultura europea y el conocimiento que ésta producía era considerado válido. Se impuso el eurocentrismo y una manera de conocer y producir subjetividades, constituyéndose así un patrón de poder epistemológico.

Está forma de colonialidad opresiva y violenta estuvo sin embargo acompañada constantemente de procesos de resistencia y de agenciamiento de los sujetos, una resistencia que es política pero también epistémica.

Un ejemplo de esta resistencia epistémica es la producción de conocimientos propios a partir de la recuperación de la memoria oral y la creación de metodologías educativas para reescribir la historia de la nación, incorporando con ello a la población afrodescendiente no desde una visión pasiva de esclavitud y victimización, sino de agenciamiento, resistencia y de lucha por la libertad y por el cumplimiento de sus derechos como ciudadanos y colectivo étnico.

La investigación que se presenta a continuación es de corte cualitativo, se realizó un análisis de literatura secundaria sobre la etnoeducación, la legislación jurídica y un análisis discursivo de los materiales impresos y de video producidos por el Centro Cultural Afroecuatoriano de la Pastoral Afro de Quito, del Fondo Afro-Andino de la Universidad Andina Simón Bolívar y del Centro de Investigación de la Mujer de Piel Africana. En estos materiales se identificaron los procesos de articulación identitaria y las estrategias de representación de los sujetos. Se realizaron además entrevistas semiestructuradas a los principales líderes y lideresas del movimiento afroecuatoriano involucrados fuertemente tanto en el proceso político como de produc- 
ción de conocimientos etnoeducativos. Estas entrevistas se complementan con testimonios actuales difundidos en internet a través de videos, publicaciones o entrevistas radiales.

Las entrevistas se enfocaron en los hechos sucedidos en esa época a fin de contextualizar la situación sociopolítica y particular de estos actores "nuevos" migrantes de Esmeraldas o del Valle del Chota a una ciudad como Quito, considerada e imaginada como blanco-mestiza. El camino recorrido por los mismos, los actuales desafíos y su posicionamiento frente a la incorporación de la etnoeducación afroecuatoriana en la malla curricular educativa.

\section{2. "Casa Adentro": La etnoeducación como posicionamiento epistemológico e identitario}

En Ecuador, el proceso de "aprender a ser negro/negra" como una posibilidad de posicionamiento frente a la discriminación, la marginalización y el racismo, estuvo marcado por actores específicos, que se apoyaron en la historia y de elementos culturales, incluso africanos, para reconstruir un "ser negro/negra" en el espacio urbano. En ese momento se fueron generando transformaciones en el significado del término "negro", como un posicionamiento de los sujetos, respaldado por la recuperación de la memoria colectiva y la construcción de un proyecto de etnoeducación. Particularmente en Quito las dinámicas de organización de colectivos empezaron a articular dinámicas locales, nacionales y transnacionales. Se destacan algunos eventos que incentivaron la organización de los afro estudiantes universitarios en las ciudades: La lucha por los derechos civiles en Estados Unidos a finales de la década de los 50 e inicios de los 60; la lucha contra el apartheid en Sudáfrica desde los 50 hasta los 90, los Congresos sobre la "Cultura Negra en América realizados en Colombia en 1977, en Panamá en 1980 y en Sao Paulo en 1982, y finalmente la denominada campaña de 500 años de resistencia indígena, negra y popular entre 1989 y 1992 (Vera, 2015).

El primer Congreso en Colombia fue organizado por el Centro de Estudios Afrocolombianos, la Fundación Colombiana de Investigaciones Folklóricas, y la Asociación de Jóvenes Negros Peruanos. Estos encuentros transnacionales pueden entenderse desde el concepto Atlántico Negro como el resultado del intercambio de experiencias y subjetividades vividas a causa de la historia de la esclavitud, la racialización y la discriminación y exclusión de los afrodescendientes en las diferentes naciones. En el segundo y tercer Congreso ya se postuló una vinculación del pasado y el presente a través de la investigación de los aportes de los afrodescendientes en las diferentes naciones, así como la importancia de incorporar la cultura negra en los sistemas educativos formales e informales, esto a través de una reivindicación social que asegure su participación de manera óptima y compatible con otros sectores (Boletín Meridiano Negro, 1980).

Después del primer Congreso, y junto con el regreso a la democracia, se fundó en 1979 en Quito el Centro de Estudios Afroecuatorianos, CEA, bajo iniciativa de jóvenes migrantes de Esmeraldas, Guayas, Imbabura y Carchi que llegaron a la capital para realizar sus estudios universitarios en la Universidad Central del Ecuador. En la ciudad de Quito se enfrentan a prácticas de racismo y discriminación constante, principalmente en el acceso a una vivienda o a la renta de dormitorios, a la búsqueda de trabajo 
y en la convivencia universitaria con compañeros y profesores blanco-mestizos.

\section{Estos estudiantes intentaban encontrar} caminos para enfrentar la discriminación, la marginalización y el racismo "por el hecho de ser negros" (Tadeo, 1998 p.72) desde el diálogo e intercambio de experiencias. Enfrentar justamente esos patrones de poder que los margina, es lo que en principio les lleva a estos estudiantes a reunirse periódicamente, conformándose así comunidades de migrantes afroecuatorianos serranos y costeños. Posteriormente un tema de debate y discusión fue el fortalecimiento de la identidad a través de la recuperación de la memoria, de los conocimientos y la sabiduría de los ancianos en sus pueblos de origen. El fin también era enseñar a la población mayoritaria estos conocimientos, historias y prácticas. Así lo narra Juan García:

\footnotetext{
En las discusiones, discusiones al principio informales, se plantearon muchas maneras de cómo llenar los vacíos tanto en las escuelas, como en la sociedad. Había varias propuestas, entre esas propuestas surgió aquella de recoger los saberes de la comunidad, no estábamos seguros si eran saberes o si eran filosofías o valores, pero sabíamos que en las comunidades había una memoria y esa memoria era lo que podía ayudarnos a fortalecer nuestra identidad pero también a enseñarle al otro sobre nosotros (Walsh, Abad \& García, 2011).
}

De esta manera Juan García en colaboración con algunos de los integrantes del CEA realizó por más de 30 años un trabajo de recuperación de memoria oral en las comunidades afrodescendientes del Valle del Chota y Esmeraldas. En 1988, publica "Cuentos y Décimas Afroesmeraldeñas", libro que recoge la voz de más de doscientos informantes conocedores de la tradición oral. Con esta recuperación de la memoria se empezaron a producir los llamados "Cuadernos Afroecuatorianos” (Pabón, 2011, p. 23) El objetivo es la recuperación del conocimiento de los mayores como un elemento base para la construcción y posicionamiento étnico identitario:

\begin{abstract}
Siempre se nos ha dicho que somos esto, que somos aquello y nosotros en nuestra reconstrucción sabemos que no somos lo que se nos dicen que somos, empezando por los mismos procesos históricos (...). Entonces empezó desde el movimiento negro una propuesta, empezamos a usar exactamente lo que antes se nos había dicho que era malo, los conocimientos que nos habían dicho que no eran conocimientos, que no valían, empezamos a usarlos para proponerlos a la gente.

Vamos a organizarnos en palenques, vamos a empezar hacer palenques de negros, las comunidades van hacer pequeños palenques y los grandes palenques van a hacer la unión de comunidades. $Y$ en todo eso empezamos a ver que los viejos tenían muchos discursos guardados que nos iban sirviendo para construir esta propuesta política de organizaciones hacia el interior de las comunidades. Se trabajó mucho con la tradición oral, con los conocimientos que la gente tenía en su cabeza (...).

La lucha es volver esta forma de conocimiento, de esta manera de entender la vida, de entender nuestros propios saberes como también insertar en los procesos educativos nuestra visión de la historia y nuestra visión del conocimiento (Walsh \& García, 2002, p. 320).
\end{abstract}

Esta narrativa discursiva evidencia el proceso de articulación de la identidad, por un lado, los discursos que interpelan "nos han dicho que somos esto, que somos aquello" $y$, por otro, un proceso de subjetividad, que García nombra como "reconstrucción", posicionándose como un ser que, atravesado por esa interpelación, se reconstruye a través de la organización de "palenques", retomando este concepto que hace referencia a territorialidades libres construidas por los esclavizados y esclavizadas 
y ahora representada como espacios de poder, de enunciación y de pertenencia; y, por otro lado, a los "conocimientos y saberes" concebidos como una herramienta para empezar a contar una historia desde sus propias voces, sentidos y experiencias.

Lo propio en este caso es representado por los discursos y conocimientos guardados en la memoria colectiva de los ancianos y ancianas, y que es trasmitida desde la tradición oral. Este rescate se constituye como una forma de preservar el conocimiento y filosofía de las comunidades negras de origen africano. Aquí la producción epistemológica y el posicionamiento político que asumen estos estudiantes da cuenta de lo que Hall (1997) ha llamado políticas de representación, ya que cuestiona y combate las raíces mismas desde donde se asienta el racismo y la discriminación, es decir la construcción discursiva de la otredad con efectos reales de negación y exclusión. Además crea representaciones nuevas, basadas en los conocimientos y en la historia contada desde la voz de los ancestros. En este sentido, la estrategia de políticas de representación hace referencia no solo a la producción de conocimientos sino que al mismo tiempo tiene el fin de ser una práctica o el inicio de un proceso de transformación social y política. Este rescate y producción de conocimientos se constituye como un espacio alternativo, un lugar de enunciación desde donde las $\mathrm{y}$ los actores involucrados van posicionando $\mathrm{y}$ fortalenciendo su identidad.

A mediados de los años 80 el CEA se desintegra en parte por falta de financiamiento $y$ porque algunos de sus líderes y lideresas después de completar sus estudios universitarios regresan a su lugar de origen. Aquellos que se quedaron en Quito se incorporaron a la
Pastoral Afro, la misma que se crea en Quito en 1981 bajo la dirección del misionero comboniano el Padre Rafael Savoia. Posteriormente se fundó el Departamento de la Pastoral Afroecuatoriana, DPA, en 1983, el Centro Cultural Afroecuatoriano, CCA, en 1985. En 1998 se fundó el Instituto de Formación Afroecuatoriana, IFA, y el Centro Juvenil Daniel Comboni. EI IFA trabaja su formación en base a 11 módulos sobre historia, economía y sociología.

El CCA orientó la formación de los afroecuatorianos, hombres y mujeres en todos los niveles, favoreciendo el surgimiento de auténticos líderes y lideresas quienes participaban en espacios de integración denominados "Encuentros de familias negras", donde cada grupo comienza un proceso de reinvención de tradiciones recreando música y danza de sus regiones de origen, y debatiendo temas sobre autoestima, valores, e identidad. El CCA se conformó como un espacio de investigación sobre la presencia de los afrodescendientes en Ecuador y su relación con América y África, en él se realizaban investigaciones, recuperación de la cultura, y de los valores de la memoria colectiva. Con estas investigaciones y los materiales que se producían se intentaba cambiar el significado negativo asociado al término negro, pero se evidencia la coexistencia de estereotipos en la construcción de su identidad étnica principalmente aquellos que vinculan la identidad con las zonas rurales, la alegría propia del pueblo afro, o la música y la danza como características supuestamente innatas de su etnia. Esto generó una serie de discursos folclóricos de la identidad afroecuatoriana, reduciéndose fuertemente a representaciones basadas en la música y en la danza. Así cada evento local o público sea político o religioso se acompañaba de los bailes típicos de las zonas ancestrales (Vera, 2015). 
África, como base, se convirtió en el punto de referencia de las prácticas culturales, sociales y religiosas de la diáspora africana en las Américas, conectando lo local con lo global. El "mito de mamá África" (De Santana, 2010) establece que los afrodescendientes alrededor del mundo se conectan por una entidad imaginada donde el pasado, la tradición, las características y el "carácter" de los afrodescendientes emerge. En este sentido, la labor de la Pastoral Afro y las obras que se empiezan a publicar muestran un vínculo con la religión y la cultura africana.

El CCA, creó la Biblioteca "Alonso de Illescas" la cual tiene alrededor de 6.500 libros, y mediante Ediciones Afro América ha publicado 90 videos y 12 programas de radio, específicamente sobre la temática afrodescendiente. Desde 1982 hasta el 2005, el CCA publicó el Boletín Informativo Afroecuatoriano Palenque. Este Boletín publicaba información de carácter local, nacional y transnacional a través del vínculo de las organizaciones afro con otras a nivel de América Latina y África, incluyendo el trabajo académico de varias universidades en el mundo, lo cual evidencia el funcionamiento del Atlántico Negro.

En 1983, la Afro Agrupación Conciencia, organizó la "Mesa Redonda sobre los Afroecuatorianos: pasado, presente y futuro en el país" (Boletín Palenque, 1983, p.1). Esta organización en Quito, más la participación de grupos en Guayaquil y Esmeraldas, apoyados por la Padre Rafael Savoia, e inspirados en la Teología de la Liberación, crearon el Movimiento Afroecuatoriano Conciencia, MAEC. Este movimiento realizó investigaciones sobre el origen de población negra en el Ecuador, la realidad de los y las afroecuatorianos ubicados en los barrios margi- nales de las diferentes ciudades, y la difusión a través de programas radiales las problemáticas que enfrentan.

El papel que juega Boletín Palenque en este proceso es muy importante ya que el MAEC logra acceder a información y a contactos con el Grupo Unión y Conciencia Negra de Brasil y de otros países en la región. EI MAEC en una documentación del movimiento escribe:

...recorrer juntos el camino realizado por el Grupo de
Unión y Conciencia Negra del Brasil, nos ayudará a
nosotros, miembros del Movimiento Afroecuatoriano
Conciencia a reflexionar dándonos ideas y sobre
todo mostrándonos un camino concreto que nuestros
amigos de Brasil van realizando (Boletín Palenque,
1984, p.1).

Integrantes de este grupo brasileño difunden sus experiencias en este medio de comunicación, en donde los intercambios sirven de guía al MAEC en el proceso de lucha contra la discriminación, el racismo y las desigualdades sociales, dentro de lo que se entiende como Atlántico Negro.

De igual manera los logros constitucionales obtenidos más tarde en Colombia a través de la Ley 70 de 1993 a nivel del derecho al territorio ancestral, pero también sobre la etnoeducación -en donde se disponía la creación de una Comisión Pedagógica de Comunidades Negras para que ejecute política etnoeducativa-, sirvieron de ejemplo a las organizaciones afro en Ecuador y en la Región Andina:

El camino a recorrer es largo, y si nuestros hermanos negros de Colombia con la Ley 70 han conseguido algunos beneficios que de alguna manera les va a ayudar para mejorar sus condiciones de vida, los negros de Ecuador y Perú tenemos que apuntar a ello, para lo cual pedimos a nuestros hermanos que están 
más avanzados nos proporcionen guías y pautas que nos permitan avanzar hacia ese mismo objetivo (Boletín Palenque, 1994, p.9).

El Padre Rafael Savoia es una figura importante en estos intercambios transnacionales, en particular, organizando los "Congresos sobre la Historia del Pueblo Negro", en donde los estudiantes universitarios involucrados con el proceso de formación podían presentar sus ponencias y discutirlas junto con otros intelectuales de la Región Andina. Estos Congresos fueron claves en los procesos de difusión de metodologías de producción de conocimientos y de reconstrucción histórica.

Las comunidades negras de Colombia y Ecuador realizaron diversos encuentros binacionales. En el IV Encuentro Binacional de Comunidades Negras de Colombia y Ecuador de 1999 se estableció como uno de los objetivos el proceso etnoeducativo de "La Gran Comarca", refiriéndose a las comunidades afrocolombo-ecuatorianas del Pacífico, en donde Juan García fue su principal representante (Boletín Palenque, 1999).

Con el quinto "Encuentro de Familias Negras" llevado a cabo en 1997, se resolvió la creación de la Federación de Organizaciones Negras de Pichincha FOGNEP, y el Movimiento de Mujeres Negras de Quito MOMUNE. Dos años más tarde se creó la Coordinadora Nacional de Mujeres Negras CONAMUNE.

La existencia de organizaciones legalmente establecidas en Quito permitió que se fortaleciera el desarrollo de propuestas etnoeducativas, las mismas que se fueron concretando desde 1999, a través de talleres llamados "Reflexión y Sensibilización" tanto en las provincias de Imbabura, Carchi, y Esmeraldas (Pabón, 2011).

En el Valle del Chota, luego de los talleres impartidos sobre la historia de África y de los Afroecuatorianos, se creó en 2001 la "Comisión de Etnoeducación", como un eje articulador de la Federación de Comunidades y Organizaciones Negras de Imbabura y Carchi, FECONIC fundada en 1997 (Pabón, 2011). La Comisión conformada mayormente por docentes hombres y mujeres afroecuatorianos y algunos líderes y lideresas, integra actualmente a más de 60 docentes.

La etnoeducación es definida por la Comisión como "un proyecto político y epistémico afroecuatoriano, que se constituye en una herramienta para acceder al conocimiento propio y en un instrumento para llegar a la interculturalidad en igualdad de condiciones y conocimientos" (Pabón, 2011, p. 28). Esta Comisión planteó en el Primer Congreso Unitario del Pueblo Afroecuatoriano "formular una reforma curricular al Sistema Educativo para que se incluya en sus contenidos conocimientos sobre la etnoeducación del pueblo negro" (Pabón, 2011, p. 30).

Tras una serie de encuentros y talleres, en 2005 la Comisión publicó el Módulo de Etnoeducación Afroecuatoriana titulado "Nuestra Historia, documento didáctico pedagógico de etnoeducación afroecuatoriana", que desde el año lectivo 2005-2006 se los aplica en las Instituciones Educativas del Valle del Chota (Pabón, 2006). En el 2008 la Comisión inició la elaboración de 13 Módulos Etnoeducativas para cada año escolar, a fin de aplicarlos en todas las instituciones de la zona norte del país. Estos módulos también tenían la intención de 
ser incorporadas en los currículos nacionales de educación intercultural (Pabón, 2011). Los módulos etnoeducativos para Educación Básica se crearon en el 2011. Desde el año lectivo 2013 se los implementa en el Valle del Chota (Pabón, 2016).

Otra institución es el Centro de Investigación de la Mujer de Piel Africana, fundada en 1991. Sus integrantes formaron también parte del CCA y luego del MAEC. Este centro integra alrededor de 60 mujeres del Valle del Chota y de la diáspora en Quito "decimos la diáspora en Quito, porque como migrantes estamos en diferentes lugares aquí en la ciudad, estamos ubicadas en diferentes barrios, pero trabajamos juntas" (Ofelia Lara7 ${ }^{7}$ entrevista octubre 2011).

El Centro, que trabaja en red con la Pastoral Afro, FOGNEP, CONAMUNE, la Red de mujeres Afrolatinoamericanas, Afrocaribeñas y de la Diáspora, y la Corporación de Desarrollo Afroecuatoriano, CODAE, nació con la idea de discutir los problemas que les afecta como mujeres, principalmente el sexismo, el machismo y la discriminación articulada por su origen (ser del Valle del Chota), ser afroecuatorianas y mujeres, intentando encontrar soluciones y alternativas en la ciudad:

En las reuniones con los compañeros nos sentábamos a conversar y veíamos que teníamos unos problemas comunes pero que había también unos problemas diferentes en el caso de las mujeres, y que había que tratarlos como mujeres para poder superar esos problemas, sobre todo del machismo, la discriminación y el racismo estructural (Ofelia Lara, entrevista octubre 2011).

El trabajo que realizan están mujeres también utiliza la metodología de "casa adentro" y "casa afuera" tras un proceso de fortalecimiento interno y de recuperación de conocimientos, el paso hacía la esfera pública se ha dado por medio de campañas a nivel local, provincial y nacional contra el machismo, la discriminación y racismo.

Las mujeres cuestionan también la producción del material educativo que se difundía en las escuelas y colegios, en donde los afrodescendientes eran solamente presentados como esclavos, como vendedores de cocada, futbolistas 0 buenos bailarines, con imágenes burlescas de su cuerpo y folclorizando su cultura. Es por eso que este Centro emprendió también un proceso de recuperación de memoria, de tradición oral, cuentos, saberes, leyendas e historias de vida de personajes en el Valle del Chota, Concepción y Salinas, a fin de incorporar estas investigaciones en la propuesta de etnoeducación pero también desde la perspectiva de género para la malla curricular, siendo este un proceso que permite dar a conocer su historia, cultura, aportes, y conocimientos, no solo a los afroecuatorianos sino a la sociedad en general:

\begin{abstract}
Nosotros hacemos más investigación de nuestra cultura, de nuestras tradiciones, de nuestra historia, de las tradiciones orales, de lo que nuestros abuelos nos contaron; nosotros ahora estamos escribiéndolo para publicar, para que sirva para la educación (...) entonces nosotros estamos en ese proceso de compilar cosas, para que sirva cuando la etnoeducación sea parte de currículo educativo, que inclusive no sea solamente para los nuestros sino también para los otros (Ofelia Lara, entrevista octubre 2011).
\end{abstract}

El Centro ha publicado entre otras investigaciones las cartillas etnoeducativas de "La Buena Mujer y el Chivo" (2008), que de acuerdo a Ofelia Lara es un cuento de la tradición oral que se trasmite en África, en Esmeraldas y el Valle del Chota -un circuito que refleja nuevamente el Atlántico Negro- "entonces ese 
significado lo usamos para decir que hemos venido de allá de África con nuestra tradición y que estamos acá, tanto en la Costa como acá en la Sierra, entonces somos los mismos" $y$, la historia de vida de "Don Perfilio Lara, el animero mayor" (Chala, 2008), siendo éste un personaje "que hacia la sacada de las almas y la venida de las almas en los tiempos de finados, todo eso es un ritual que se práctica en nuestras comunidades", y un Diccionario de Choteñismos es decir, palabras propias del Valle del Chota (Ofelia Lara, entrevista octubre 2011). El Centro tiene varias investigaciones que por falta de financiamiento no han sido aún publicadas.

En la Concepción, el Centro forma parte también de la Escuela de la Tradición Oral, la Voz de Tus Ancestros, ETOVA, fundada en el 2007, también con el objetivo de recopilar los saberes, de los ancianos y ancianas de la región. La escuela está integrada entre otros por Barbarita Lara, Ofelia Lara, Iván Pabón quienes también forman parte de la "Comisión de Etnoeducación”, encargada de la producción actual de módulos etnoeducativos. Esta Escuela se ha constituido como un espacio político y de producción de conocimientos propios.

Para la Escuela, el Maestro Juan García se constituye el "Padre de la Cultura", la filosofía que lleva la Escuela ha tomado los legados y la propuesta didáctica y metodológica que el Maestro a lo largo de los años ha ido desarrollando:

él es el enunciador de esta preocupación de empezar a recuperar la memoria, entonces al maestro lo conocimos, así como mochilero, andando, investigando, escuchando y grabando a los mayores, él es una guía en este proceso, su legado material está en el Fondo Afro Andino (Ofelia Lara, entrevista Octubre 2011).
En efecto, en 2002, el "Proceso de Comunidades Negras”, representado por Juan García firmó un convenio con la Universidad Andina Simón Bolívar, en Quito, institución a la cual entregó en comodato 8.000 fotografías y una extensa colección de 3.000 horas de cintas magnetofónicas de testimonios de afroecuatorianos, con ello se creó el Fondo Documental Afro-Andino, y más tarde se impulsó la Cátedra de Estudios de la Diáspora Afro Andina, financiada por el Proyecto Andrés Bello. El material que posee el Fondo Afro-Andino se constituye en un elemento para fortalecer las identidades afroecuatorianas y también para ser utilizado como herramienta de etnoeducación a través de la tradición oral.

En la Cartilla "La Tradición Oral, una herramienta para la Etnoeducación, una propuesta de las comunidades de origen africano para aprender casa adentro", publicada en el 2003 define 5 ejes fundamentales por los que deben pasar las propuestas etnoeducativas: 1. Identidad y pertenencia. 2. Territorios y tierras ancestrales, 3. Uso y manejo de recursos naturales. 4. Cultura y prácticas tradicionales, 5. Historia comunitaria (García, 2003a, p. 16). Esa es una propuesta educativa y pedagógica muy vinculada a las políticas de representación ya que produce conocimientos propios, es decir, desde los conocimientos ancestrales trasmitidos desde la oralidad y como un posicionamiento político de las comunidades afroecuatorianas.

El Fondo Documental Afro-Andino con el material recopilado por el CEA y la metodología que el maestro Juan García desarrolló, se publicaron dos Guías Didácticas "Cuentos de Animales en la Tradición Oral del Valle del Chota" (García, 2003b) y "Papá Roncón, Historia de Vida" (García, 2003c) y el libro 
"Pensar sembrando/sembrar pensando con el Abuelo Zenón" (Walsh \& García, 2017).

La guía "Cuentos de Animales en la Tradición Oral del Valle del Chota" está orientada a resignificar la función social de la tradición oral como un legado ancestral que tiene como base África, y que de ese legado se sostiene la identidad.

La segunda guía "Papá Roncón, Historia de Vida", aborda cinco temáticas relacionadas con la experiencia vivida de Guillermo Ayoví, -principal exponente de la música Marimba- y su interrelación con los mandatos ancestrales dentro de la diáspora africana: 1. Territorio, tradición e identidad; 2 . Uso y manejo de los recursos naturales; 3.Cosmovisión y religiosidad, 4. Saberes y tradiciones; 5. Relaciones interculturales, mandatos y enseñanzas de los mayores.

El libro "Pensar sembrando/sembrar pensando con el Abuelo Zenón" también fue trabajado en cinco tramos: 1. Sobre siembras en y desde los territorios ancestrales; 2 . Identidad, saber y hacer cultural; 3. El caminar y andar de la tradición oral; 4. Resistencia, historia, memoria; 5. Desterritorialización. El Abuelo Zenón representa el personaje que simboliza y expresa la memoria colectiva y saberes ancestrales afroecuatorianos.

El Fondo Afro-Andino publicó además tres Cartillas Etnoeducativas Aprender Haciendo: "Una metodología para la reconstrucción de saberes" (León \& Walsh, 2007); "Metodología de la Investigación Colectiva" (León \& Santa Cruz, 2008), que recoge la experiencia de investigación colectiva del proyecto Saberes propios, religiosidad y luchas de existencia afroecuatoriana, y "Plantas Medicinales del Valle del Chota" (Santa Cruz \& Pineda, 2009), la cartilla recoge los conocimientos del grupo de Mujeres de la Tercera Edad del Valle del Chota. La metodología indica que es importante entender que la "tradición oral está en la cabeza de nuestros mayores", estos son considerados "autoridades y maestros", son los "guardianes de la tradición", ya que en la cultura afroecuatoriana hay suficientes elementos para "reconstruir nuestras identidades" y finalmente, comprometerse a devolver esos saberes y conocimientos a las futuras generaciones (León \& Walsh, 2007, p. 8). Estos libros y cartillas se constituyen en una puesta metodológica-pedagógica, en donde se presentan reflexiones dialógicas sobre los distintos ejes.

La etnoeducación se constituye de esta manera en un lugar de enunciación en donde lleva implícito un proceso de desprenderse de lo ajeno, es decir, de todas las construcciones esencialistas, negativas y estereotipadas que se ha construido sobre ellos bajo la colonialidad del poder, para reapropiarse de lo propio a través las narrativas, historias, memorias, sentidos, saberes y conocimientos del pueblo afroecuatoriano.

Como se analizará en el siguiente apartado la movilización de la sociedad civil afroecuatoriana con el apoyo de la iglesia a través de la Pastoral Afro logró el reconocimiento de "pueblo afroecuatoriano" como un grupo étnico con derechos colectivos particulares. Se evidencia que la lucha contra la discriminación y el racismo se acompañó de una fuerte propuesta hacia la difusión de su historia, cultura y producción epistemológica. 
3. "Casa Afuera": Incidencia política del Pueblo Afroecuatoriano en los estamentos legales sobre la etnoeducación

El punto de partida para cuestionar en la esfera pública la discriminación a los afroecuatorianos en la ciudad de Quito, se dio tras una serie de asesinatos de hombres y mujeres afroecuatorianos, algunas de ellas en manos de la Policía entre 1995 y 1997 (Ocles, 2009).

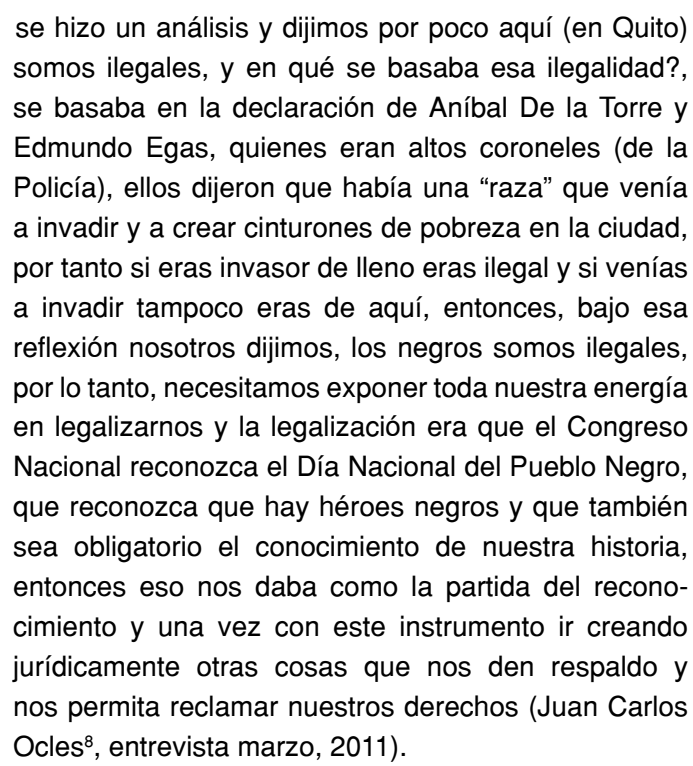

Los afroecuatorianos fueron interpelados como "invasores", "ilegales", ante las declaraciones de estos miembros de la Policía, las diversas organizaciones afro, coordinadas por la FOGNEP, la CONAMUNE y la Pastoral Afro de la ciudad de Quito, se movilizaron el 7 de enero de 1997, en dirección a la Corte Suprema de Justicia y hacia el Ministerio de Gobierno. Con la marcha "Por un Futuro Negro, Digno y Bonito" -considerada "el Primer Grito de Protesta Pública" y recordada como el "Día Nacional de la Dignidad Afroecuatoriana" (Boletín Palenque 1997, p.16)- se exigió que los casos sean juzgados y que las familias sean indemnizadas. Los casos no fueron juzgados, las familias tampoco fueron indemnizadas, sin embargo, se generó por primera vez en la esfera pública una muestra de exigencia de respeto a sus derechos como seres humanos.

El 1 de octubre de 1997 nuevamente se produjo una marcha masiva por parte de las organizaciones afroecuatorianas, esta vez en dirección al Congreso Nacional con el fin de exigir la "Ley especial de la Institucionalización del Día Nacional del Negro y el Reconocimiento como Héroe Nacional a Alonso de Illescas". Mediante Resolución Legislativa firmada el 2 de octubre de 1997, y publicada en Registro Oficial el 4 de Noviembre de 1997, el Congreso Nacional declaró el primer domingo de Octubre como el Día Nacional del Pueblo Negro, reconoció a Alonso de Illescas como Primer Héroe Nacional, y a más de ello recomendó la inclusión de estos hechos en la historia nacional.

De estos acontecimientos se destacan dos aspectos importantes que hacen referencia a las articulaciones identitarias y a las estrategias de representación que ponen en práctica los sujetos para cuestionar modificar o intervenir en los regímenes racializados de representación y con ello generar espacios de diálogo e intervención:

1. El slogan "Por un Futuro Negro, Digno y Bonito" evidencia una reinversión de estereotipos, como una estrategia para incidir en las relaciones de representación, es decir, en los discursos que históricamente han ubicado a los afrodescendientes en posiciones de inferioridad y exclusión, y las representaciones que sustentadas en prejuicios y estereotipos han creado imágenes negativas y subordinadas, 
en palabras de Orfa Reinoso ${ }^{9}$ las marchas y los plantones en la ciudad tenían como objetivo que se reconozca a los afroecuatorianos como "parte fundamental del país" y que se reconozca el aporte que el pueblo afroecuatoriano ha dado a la Nación, pero no desde la mirada esencialista, racializada y estereotipada con la que normalmente han sido interpelados:

\footnotetext{
...que se reconozca que nosotros también somos parte fundamental del país, que no se nos discrimine, (...) porque nosotros también hemos hecho historia, nosotros hemos aportado, que se reivindique toda esa cuestión de la negritud y que nazca esto como una propuesta, realmente una propuesta social, política, cultural y económica, donde nosotros decíamos que se nos mire desde la otra cara de la moneda, no lo típico, ladrón, ó en el positivo, supuesto para ellos, desde lo deportivo, desde lo gastronómico, desde lo atlético y pare de contar, sino más bien viendo desde un contexto bastante amplio, para que se dejen esos actos discriminatorios (Orfa Reinoso, entrevista marzo 2011).
}

Con la movilización, este posicionamiento se asumió como parte de un proceso de articulación de la identidad. Los afro en Quito fueron interpelados como "migrantes", "campesinos", "pobres", "invasores", "peligrosos racialmente", como una "raza proclive a la delincuencia" y en lo positivo solo como buenos "músicos", "bailarines", "cocineros" y "deportistas"; es decir, un régimen racializado de representaciones que se ha construido históricamente y que ha utilizado los medios de comunicación, los discursos populares y al sistema educativo para reproducir discursos y legitimarlos, convirtiendo ciertos estereotipos en realidades naturalizadas. Ante este régimen racializado de representaciones, mujeres y hombres afros modificaron esas representaciones en un proceso de subjetivación reivindicando la "dignidad de ser" y la "negritud" como una propuesta y posición política al exigir primero su reconocimiento y respeto como seres humanos, segundo como ciudadanos y tercero como un grupo cultural diverso que reconoce su historia y los aportes que han hecho en la construcción del Estado Nación.

Un "Futuro Negro, Digno y Bonito" es justamente una posición política asumida por la FOGNEP y la CONAMUNE a manera de lucha por los derechos a la vida, al respeto $y$ a la diversidad cultural y étnica. La movilización fue una forma de posicionamiento, puesto que en la marcha de 1997, por primera vez, la voz del pueblo afro se hizo escuchar en la ciudad de Quito, los sujetos crearon un lugar de enunciación y con ello, dieron el primer paso para generar su reconocimiento como colectivo étnico-cultural y político por parte de sociedad y el Estado ecuatoriano.

2. Al momento que las organizaciones exigieron el reconocimiento del Día Nacional del Negro a Alonso de Illescas como primer héroe negro nacional, y la incorporación de estos hechos a la historia nacional, evidencia la generación de políticas de representación, lo cual se produce al intervenir en los discursos, resaltando a partir de representaciones propias, elementos de auto identificación que permitan a los sujetos posicionarse. La imagen y biografía de Alonso de Illescas se convirtió en símbolo y estandarte de lucha histórica del pueblo afroecuatoriano. En efecto, se debe mencionar que la difusión de la obra de Miguel Cabello Balboa sobre la llegada de los negros al Ecuador, y en particular sobre Alonso de Illescas, como fundador del primer reino cimarrón en Esmeraldas, conocido por los historiadores como el "Reino de los Zambos", se constituyó en uno de los hallazgos más signi- 
ficativos para los afroecuatorianos. A partir del conocimiento y difusión de los contenidos de esta obra en la publicación del IFA: Historia del Negro en el Ecuador (1997), el pueblo afroecuatoriano fortalece su proceso de reivindicación y construcción política identitaria.

A nivel estatal y frente a la fuerte demanda del movimiento afroecuatoriano en el año 2000 se creó el cargo de Director Nacional de Defensa de los Derechos del Pueblo Afroecuatoriano. En 2002 empieza a funcionar la CODAE, en 2006 se expidió la Ley de Derechos Colectivos de los Pueblos Negros Afroecuatorianos. En esta Ley se estableció en su artículo № 8 que para la formulación de las políticas de etnoeducación de los pueblos negros o afroecuatorianos se creará a través del Ministerio de Educación y Cultura, la "Comisión Pedagógica Nacional de Asuntos Afroecuatorianos”. Se estableció además en su artículo №5 que en los planes y programas de educación básica y de bachillerato, constaran, como eje transversal, el conocimiento de las culturas negras o afroecuatorianas del país.

A nivel distrital en Quito también se empezaron a dar cambios: la Ordenanza Metropolitana para la Inclusión Social con enfoque étnico-cultural del pueblo afroecuatoriano en el Distrito Metropolitano de Quito 0216, expedida en julio del 2007, dispuso en su artículo 2: "incorporar al Subsistema Metropolitano de Educación, los contenidos de historia, cultura afroecuatoriana y etno-educación".

De igual manera, en la Constitución de 2008, en el artículo 343, se indica que "El sistema nacional de educación integrará una visión intercultural, acorde con la diversidad geográfica, cultural y lingüística del país, y el respeto a las comunidades pueblos y nacionalidades".
En el Plan Plurinacional para Eliminar la Discriminación Racial y la Exclusión Étnica y Cultural del 2009, también se establece en el eje 3 sobre Educación, Comunicación e Información, considerar el Programa de Educación para la Interculturalidad, mediante el cual se plantea una reforma al currículo educativo, a fin de incorporar la etnoeducación afroecuatoriana. Para ello se propuso crear la "Cátedra de Estudios Afrodescendientes", la cual debería ser obligatoria en todos los planteles educativos del país.

Posteriormente, en 2011, se expidió la Ley Orgánica de Educación Intercultural, la misma que fomenta la educación intercultural e inclusiva, en donde entre sus obligaciones se garantiza en el literal g: "El diseño curricular considerará siempre la visión de un Estado Plurinacional e Intercultural". Entre los fines del Sistema de Educación Intercultural Bilingüe se establece en su literal d: "La recuperación, desarrollo y socialización de la sabiduría, el conocimiento, la ciencia y la tecnología de los pueblos y nacionalidades ancestrales".

En 2013 la Asamblea General de las Naciones Unidas proclamó el Decenio Internacional de los Afrodescendientes 2015-2024 con el lema "Afrodescendientes: Reconocimiento, Justica y Desarrollo". Con respecto a la educación se establece que dentro de las medidas que debe atender la Asamblea General está el poner en marcha una campaña de sensibilización para informar al público en general sobre la historia, las contribuciones, así como las experiencias contemporáneas y la situación de los derechos humanos de los afrodescendientes. En 2016 el gobierno ecuatoriano declaró como política nacional el cumplimiento de los objetivos y metas del programa de actividades del Decenio. 
La incorporación de la Etnoeducación y su incidencia en las leyes y en las políticas públicas responde como hemos visto a un camino recorrido por la sociedad civil afroecuatoriana desde finales de los 70 y con mayor fuerza desde 1999. Esta ha sido una lucha marcada por la colonialidad del poder, un colonialismo interno que desde la discriminación institucionalizada de los Gobiernos de turno, ha postergado la implementación de la etnoeducación afroecuatoriana por prácticamente dos décadas. Es solo hasta 2015 que por gestiones de la asambleísta y líder afroecuatoriana Alexandra Ocles se concretó espacios de diálogo entre la Comisión Nacional de Etnoeducación Afroecuatoriana dirigida por Iván Pabón y el Estado. Tras la reunión, el Ministro Espinosa dispuso que se incorpore y operativice la etnoeducación afroecuatoriana en la malla curricular a nivel nacional:

Las organizaciones afroecuatorianas venimos trabajando esto (la etnoeducación) desde 1999, hemos insistido, hemos pedido citas a todos los Ministros de Educación de turno y no hemos tenido respuesta, no hemos tenido respuesta del Estado (...).

Es a partir prácticamente del 2013 con el nuevo Ministro Augusto Espinosa que retomamos este proceso, se le presentó una primera carta en el gabinete itinerante en lbarra, y desde ahí, (...) él delegó a Luis Males el Subsecretario de Educación Intercultural Bilingüe con quien tuvimos tres reuniones, sin concreciones, sin concreciones!, y es esta reunión del 17 de Septiembre (del 2015) que tuvimos en la Unidad Educativa del Milenio en Piquiucho que marca un ícono y marca la evolución y revolución si cabe el término en todo este proceso (...). El Ministro pudo mirar toda nuestra historia, todo nuestro contexto (..) finalmente el Ministerio terminó pidiendo perdón por su ignorancia, por su desconocimiento sobre nuestra existencia, (...) la cita que logramos con el Ministro fue gracias a las gestiones de la Asambleísta Alexandra Ocles (...) ella es una de estas 11 personas que iniciaron en 1970 ella también es parte de este proceso y la lucha también lo ha asumido ella (Pabón, 2016).
Bajo Acuerdo Ministerial Nro. MINEDUCME-2016-00045-A, con fecha mayo del 2016, el Ministro de Educación Augusto Espinosa acuerda reconocer e implementar la etnoeducación afroecuatoriana en el sistema nacional de Educación.

Establecer la "Mesa de Etnoeducación Afroecuatoriana", como instancia de interlocución, asesoría y diálogo permanente con la Autoridad Educativa Nacional a través de la Subsecretaría de Educación Intercultural Bilingüe. Esta instancia estará integrada por diez docentes afroecuatorianos, elegidos de manera participativa, con criterios de alternancia y distribución territorial. Los integrantes de la Mesa durarán en sus funciones dos años, y podrán ser reelegidos después de un período (Acuerdo MINEDUC-ME-2016-00045-A. Art. 2, p. 2).

El artículo 3 dispone a la Subsecretaría de Educación Intercultural Bilingüe la incorporación de profesionales afroecuatorianos con conocimientos en etnoeducación, para coordinar y apoyar en la elaboración de materiales curriculares y didácticos con pertinencia cultural como herramientas de apoyo al proceso de enseñanza -aprendizaje en el Sistema Nacional de Educación. Actualmente la Mesa, continúa elaborando 13 módulos de etnoeducación afroecuatoriana.

El artículo 4 del mencionado Acuerdo Ministerial dispone que en reconocimiento a la tradición cultural y oral afroecuatoriana, la Subsecretaría de Educación Intercultural Bilingüe designe como "Guardianas de los Saberes", a aquellas instituciones educativas que tengan significativa presencia de población afrodescendiente o que estén ubicadas en territorios ancestrales o de mayor presencia poblacional, esto sería de acuerdo al Censo del 2010 en las provincias de Guayas, Esmeraldas, Pichincha, Imbabura, y Carchi (INEC 2010). En función de lo que dispone el Acuerdo, en estas instituciones educativas se 
debería incorporar con énfasis el enfoque de etnoeducación en el proceso educativo institucional. Hasta el momento solo se han reportado dos instituciones en Imbabura, dos en Carchi, dos en Pichincha, y tres en Esmeraldas para recibir la designación de centros "Guardianas de los Saberes" (Informe Alternativo, 201710).

La reforma curricular debería incluir la etnoeducación afroecuatoriana en las diversas áreas: ciencias sociales, ciencias naturales, matemáticas, lengua y literatura, educación cultural y estética. La currícula debe incluir la historia del pueblo afroecuatoriano, su cultura, sus aportes a nivel de conocimientos ancestrales en la agricultura y la medicina, así como la inclusión de canciones como los chigualos y los arruyos, leyendas, poemas y las décimas. También la difusión de obras artísticas pertenecientes a las provincias de Imbabura y Esmeraldas (Etnoeducación y Propuesta Curricular 2016, Ministerio de Educación).

En la Agenda Nacional para la Igualdad del Pueblo Afroecuatoriano 2015-2024 publicada por la Corporación de Desarrollo Afroecuatoriano, CODAE en 2015 se establece a más de la implementación de la asignatura de "Educación Cimarrona Afroecuatoriana" en todos los niveles de escolaridad, la implementación de la cátedra de "Estudios Afrodiaspóricos" en las universidades del país, haciendo énfasis en la lucha contra el racismo y la discriminación fenotípica cultural. De igual manera la Agenda impulsa la creación de Museos de las culturas y pueblos a fin de difundir el conocimiento del acervo cultural del pueblo afroecuatoriano, y la investigación y difusión de conocimientos vinculados a la historia, cultura y política del pueblo afroecuatoriano (Agenda Nacional para la Igualdad del Pueblo Afroecuatoriano 2015-2024, 2015, pp.105-106).
La etnoeducación afroecuatoriana incluida en la malla curricular es entonces una realidad desde finales de 2016, sin embargo, el Ministerio de Educación aún continúa elaborando los módulos educativos para ser implementados a nivel nacional. Estos módulos, como se ha indicado, son trabajados por un equipo compuesto por académicos afroecuatorianos que desde su militancia política han trabajado "casa adentro" y "casa afuera" a fin de fomentar la construcción de una nación intercultural, entendida esta como un proceso político, epistemológico alternativo e incluyente.

\section{Conclusiones}

En este artículo se ha analizado el proceso de incorporación de la etnoeducación afroecuatoriana considerándose este como un posicionamiento identitario, político y epistemológico del pueblo afroecuatoriano. El análisis se presenta en dos momentos "casa adentro" y "casa afuera". En el momento "casa adentro" los y las integrantes del CEA y MAEC, realizaron un proceso de buscar un lugar desde el cual puedan posicionarse y hablar. Es decir, se encontraban en una ciudad construida como blanca mestiza que los excluía, marginaba y discriminaba por su condición racial y de clase. Frente a esta realidad, estas organizaciones apoyadas por la CCA generaron un proceso de redescubrimiento y búsqueda de sus raíces, desde las cuales puedan sostenerse y construir un lugar de enunciación. Es así que estando en la ciudad, y bajo la guía de Juan García, grupos de estudiantes tienden estratégicamente a retornar a sus lugares de origen para reconstruir elementos mediante los cuales puedan forjar una política de identidad y con ello resistir a la exclusión, marginalización, racismo y discriminación. En sus lugares de origen, los 
elementos que encuentran es la tradición oral: las narrativas, historias, hechos, conocimientos y saberes que han estado históricamente subordinados y ocultados por la sociedad blanco-mestiza dominante bajo la colonialidad del poder. Estas organizaciones empezaron entonces a generar una nueva política de representación de lo que ellos consideraban que son, una noción de etnicidad, de grupo étnico positiva, con una producción cultural propia plasmada en lo que sería la etnoeducación.

En el momento "casa afuera" la FOGNEP y MOMUNE apoyadas de igual manera por la CCA se hacen presentes en la esfera pública a través de marchas en la ciudad de Quito. El detonante para salir a la calle y exigir el respeto a su ser se dio tras el asesinato de hombres y mujeres negras en la ciudad capitalina. El respeto a su ser se manifestó con el respeto a ser negro y negra. Estratégicamente desde una modificación en las relaciones de representación usaron el slogan Por un Futuro Negro, Digno y Bonito. Un futuro negro implica una reapropiación del término negro. Justamente el término que era usado por las clases dominantes, blanco-mestizas para llamar peyorativamente a los y las migrantes. Aquí el término negro asumido por las organizaciones no es visto como una cuestión de pigmentación, aquí el término negro es asumido como una categoría histórica, política y cultural, que les permitió posicionar una identidad étnica como motivo de orgullo y dignidad.

Haciendo uso de lo construido en el primer momento "casa adentro", las organizaciones presentan un pedido de reconocimiento para validar su existencia. La cultura e historia afroecuatoriana es introducida en este momento como una política de representación que dio paso a una modificación en la legislatura a fin de ser reconocidos como pueblo con derechos colectivos.
El vínculo "casa adentro" y "casa afuera" también se evidencia cuando Juan García en representación del Proceso de Comunidades Negras entrega en comodato el material que fue recopilado desde el CEA, y el MAEC a la Universidad Andina, lo cual llevó a la creación del Fondo Afro-Andino. Es decir, en este momento tanto la academia como las organizaciones civiles realizan un trabajo en conjunto para, con base en el material recopilado, producir materiales etnoeducativos y continuar el trabajo de recuperación de memoria desde la tradición oral. La producción de materiales impresos, así como de videos, y los talleres que se han difundido por parte de esta institución bajo el liderazgo de Juan García, permitieron construir una propuesta metodológica de etnoeducación. Este proceso evidencia la construcción de políticas de representación propias que llevaron a la incorporación de la etnoeducación en el sistema educativo a nivel nacional.

El proceso, como se ha evidenciado a lo largo de esta investigación, no ha sido fácil. Ha pasado por un sin número de trabas burocráticas que dan cuenta de la existencia de un racismo estructural y una discriminación institucionalizada.

La sociedad civil afroecuatoriana ha generado propuestas políticas educativas epistemológicas que después de décadas de lucha se están empezando a concretar. El efecto que cause en las futuras generaciones que se eduquen con este nuevo sistema educativo, permitirá construir una sociedad intercultural más incluyente, en donde sus miembros respeten sus diferencias culturales, sin jerarquías raciales, sin violencia y contrarrestando principalmente el régimen racializado de representaciones y las estructuras que aún sustentan las prácticas discriminatorias y racistas en la sociedad ecuatoriana. 


\section{Notas}

${ }^{1}$ El concertaje se entiende como un contrato mediante el cual un indígena se obligaba a realizar trabajos agrícolas de manera vitalicia y hereditaria, sin recibir salario o recibiéndolo mínimo. (Real Academia de la Lengua Española, versión on line). De acuerdo con el concepto dado por CEPAL citado en Galarza (2010), el huasipungo es un sistema que proviene de la antigua encomienda española, y que consistía en la prestación de trabajo durante varios días a la semana en pago del usufructo de una parcela y del uso de una choza.

${ }^{2}$ En Ecuador el delito de discriminación racial es punible desde 1979 y el delito de odio racial a partir del 2014. Según la Fiscalía General del Estado hasta el 2017 a nivel nacional existieron 314 denuncias por discriminación y 963 denuncias por actos de odio. Solo un caso de delito de odio racial fue llevado a sentencia en el 2016.

${ }^{3}$ La pobreza por necesidades básicas insatisfechas es del $32.5 \%$ en el 2015. De acuerdo con el SIISE: "se considera pobre a una persona si pertenece a un hogar que presenta carencias persistentes en la satisfacción de sus necesidades básicas, incluyendo vivienda, salud, educación y empleo" (Antón, 2016, p. 50).

${ }^{4} \mathrm{Si}$ bien la tasa de asistencia a la educación básica de los afrodescendientes $(89,05 \%)$ es ligeramente inferior al promedio nacional (91\%), las distancias se acrecientan a medida que se avanza en el sistema educativo. Así, según las cifras del censo de 2010, mientras que los blancos alcanzan en promedio 10,7 años de escolaridad, los afroecuatorianos alcanzan 8,4 . Solo 5 de cada 100 afroecuatorianos mayores de 24 años han alcanzado títulos de educación superior en disciplinas profesionales (INEC, 2010).

${ }^{5} \mathrm{El} 57,2 \%$ de los hogares afroecuatorianos no cuenta con servicios adecuados de agua, sistema de alcantarillado y de recolección de basuras (INEC, 2010).

${ }^{6}$ Juan García llamado por los afroecuatorianos Maestro "guardián de la tradición y la memoria", es conocido por las comunidades

\section{Referencias Bibliográficas}

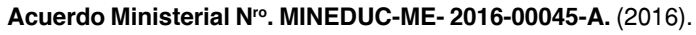
Quito: LEXIS

Agenda Nacional para la Igualdad del Pueblo Afroecuatoriano 2015-2024 (2015). Quito CODAE.

Andrews, G. (2007). Afro-Latinoamerica 1800-2000. Frankfurt: Vervuert.

Antón, J. (2016a). Pobreza y afrodescendencia en Ecuador. Repique, (1), 44-68.

Boletín Meridiano Negro (1980). Esmeraldas: Taller Editores.

Boletín Afroecuatoriano Palenque (1983, 1984, 1994, 1997, 1999). Quito: Centro Cultural Afroecuatoriano.

Costa, S. \& Gurza, A. (2006). Cohesión social y coexistencia como "bambero mayor", Juan García se posicionaba a su vez como "obrero del proceso". Fue iniciador del Proceso de Comunidades Negras, del Consejo Nacional de Palenques, de la propuesta de creación de la Gran Comarca en Esmeraldas y de la Comisión de Etnoeducación Afroecuatoriana. En 1989 realizó una maestría en Historia en la Universidad John Hopkins en Estados Unidos. Es autor de más de 30 libros y artículos, ha recibido varios premios y reconocimientos nacionales e internacionales por sus contribuciones intelectuales y culturales. En 2011, fue nombrado profesor honorario de la Universidad Andina Simón Bolívar.

${ }^{7}$ Líder afroecuatoriana, egresó de Doctora en Medicina General, formó parte de la Pastoral Afro, del CEA y del MAEC. Forma parte de la Comisión de Etnoeducación. Se ha especializado en medicina tradicional afro.

${ }^{8}$ Líder afroecuatoriano, Doctor en Jurisprudencia y Abogado de los Tribunales de la República del Ecuador, es experto en Derechos Humanos. Formó parte del grupo Martín Luther King en los 90. Fue Presidente, FOGNEP de 1997 hasta 2001. Coordinador Técnico de la Dirección Metropolitana de Inclusión Social dentro del Programa de Desarrollo Afroecuatoriano en el Municipio del Distrito Metropolitano de Quito desde el año 2001. Fue Presidente de la Asociación Afro -29 de Junio, "Por la Plena Vivencia de los Derechos Humanos 1996-2000. Fue Concejal de Quito en el 2011 y es coordinador del Centro de Desarrollo y Equidad Racial "Desmond Tutu”- CEDESTU.

${ }^{9}$ Líder afroecuatoriana perteneciente a la organización Negra Bonita en los 90, y presidenta de la FOGNEP. Directora de Diversidad e Interculturalidad de la Subsecretaria de Pueblos 2014.

${ }^{10}$ Informe Alternativo, Examen de los informes presentados por los Estados partes en virtud del artículo 9 de la Convención ECUADOR - 2017. intercultural en América Latina. En Cotler, J. (ed.). La cohesión social en la Agenda de América Latina y de la Unión Europea. (pp. 247-276). Lima: Ediciones Instituto de Estudios Peruanos.

Constitución de la República del Ecuador de 2008. Quito: LEXIS. Chalá, M. (2008). Historia de vida, Don Perfilio Lara. El animero Mayor. Quito: Ministerio de Cultural, PRODECI, ETOVA.

Chaves, M. (2009). Revoluciones esclavas en el contexto de la Independencia en el caso del Ecuador. Disponible en: http:// lasa.international.pitt.edu/members/congresspapers/lasa2009/files/ ChavesMariaE.pdf

De Santana, P. (2010). Mama África, Reinventing Black in Bahia, Durham: Duke Unversity Press. 
Distrito Metropolitano de Quito (2008). Ordenanza Metropolitana para la Inclusión Social con enfoque étnico-cultural del pueblo afroecuatoriano en el Distrito Metropolitano de Quito, N. 0216, Serie Cuadernos de Etnoeducación, N. 7. Quito: CEDESTU, PNUD, Alcaldía Metropolitana de Quito.

Etnoeducación y Propuesta Curricular 2016 (2016). Quito: Ministerio de Educación, documento sin publicar.

Galarza, J. (2010). El yugo feudal. Visión del Campo Ecuatoriano, Quito: CCE Benjamín Carrión Ediciones.

García, J. (2003a). La tradición oral, una herramienta para la etnoeducación. Una propuesta de las comunidades de origen afroamericano para aprender casa adentro. Quito: FEDOCA, Genesis Ediciones.

(2003b). Guía Didáctica Cuentos de Animales en la Tradición Oral del Valle del Chota, Quito: Fondo Documental AfroAndino, Universidad Andina Simón Bolívar.

(2003c). Guía Didáctica. Papá Roncón - Historia de

Vida. Quito: Fondo Documental Afro-Andino, Universidad Andina Simón Bolívar.

Gilroy, P. (1993). The Black Atlantic, Modernity and double consciousness. Cambridge Massachusetts: Harvard University Press.

Hall, S. (1996a). Introduction: Who Needs Identiy?. En Hall, S. \& du Gay, P. (eds.), Questions of Cultural Identity (pp. 1-18). London: Sage. (1996b). New identities. En Morley, D. \& Chen, H. (eds.), Stuart Hall Critical Dialogues in Cultural Studies (pp. 442-452). London, New York: Routledge.

(1997). The spectacle of the other. En Hall, S. (ed.), Representation: Cultural representation and signifying practices (pp. 223-290). London: Sage Open University.

(2001). Negotiation Caribbean identities. En Castle G. (ed).

Postcolonial Discourse, An Anthology (pp. 281-292). Oxford: Blackwell.

Informe Alternativo, Examen de los informes presentados por los Estados partes en virtud del artículo 9 de la Convención ECUADOR . (2017). Fundación de Desarrollo Social Afroecuatoriana Azúcar - Enlace país de la Red de Mujeres Afrolatinoamericanas, Afrocaribeñas y de la Diáspora. Disponible en: http://tbinternet.ohchr. org/Treaties/CERD/Shared\%20Documents/ECU/INT_CERD_NGO_ ECU_28065_S.pdf

INEC (2010). Censo de Población y Vivienda 2010, Quito: INEC.

IFA (1997). Historia del Negro en el Ecuador. Quito: Centro Cultural Afroecuatoriano.

Ley Orgánica de Educación Intercultural (2011). Quito: LEXIS. Ley de Derechos Colectivos de los Pueblos Negros Afroecuatorianos (2006). Quito: LEXIS.

León, E. \& Walsh, C. (2007). Cartilla Etnoeducativa 1. Aprender Haciendo. Una metodología para la reconstrucción de saberes. Quito: Fondo Documental Afro-Andino, Universidad Andina Simón Bolívar.

León, E. \& Santa Cruz, L. (2008). Cartilla Etnoeducativa 2. Aprender Haciendo. Metodología de investigación Colectiva. Quito: Fondo Documental Afro-Andino, LASA, Universidad Andina Simón Bolívar.

Lucena, M. (1994). Sangre sobre piel negra: la esclavitud quiteña en el contexto del reformismo borbónico. Quito: Abya Yala.

Ocles, J. (2009). La discriminación racial en el ordenamiento jurídico ecuatoriano. Cuaderno de Etnoeducación № 10, Quito: Municipio de Quito.

Pabón, I. (2011). Estudios sobre educación con poblaciones afrodescendientes. En Robalino, M. \& Venegas, H. (coord.) Rutas de la Interculturalidad. Estudios sobre educación con poblaciones afrodescendientes en Ecuador, Bolivia y Colombia. Enfoques, experiencias y propuestas (pp. 17-71). Quito: UNESCO.

(Coord.) (2006). Módulo didáctico nuestra historia. Comisión de etnoeducación de la Federación de Comunidades y Organizaciones Negras de Imbabura y Carchi. En Alvarez, C. (ed.). Historias desde el Aula, Educación intercultural bilingüe y etnoeducación en Ecuador. Compilación de textos enviados al concurso de sistematización de experiencias en educación intercultural bilingüe y etnoeducación (pp. 51-62). Quito: Abya Yala.

(2016). Programa entre Pueblos. Radio de la Asamblea Nacional. Disponible en: http://laradio.asambleanacional.gob.ec/ programas/entre-pueblos/941-etnoeducacion-y-dia-del-periodistaecuatorianos

Quijano, A. (1992). Colonialidad y Modernidad/Racionalidad. Revista Perú Indígena, (13), 11-20.

(2000). Colonialidad del Poder, Eurocentrismo y América Latina. En Lander, E. (Comp.) La Colonialidad del Saber: Eurocentrismo y Ciencias Sociales (pp. 201-346). Buenos Aires: CLACSO.

Ordenanza Metropolitana para la inclusión social con enfoque étnico - cultural del pueblo afroecuatoriano en el Distrito Metropolitano 0216, Serie Cuadernos de Etnoeducación N. 07. Quito: CEDESTU, PNUD, Municipio Metropolitano de Quito.

Restrepo, E., Walsh, C. \& Vich, V. (eds.) (2010). Stuart Hall, Trayectorias y problemáticas en los estudios culturales. Envion Editores, Instituto de Estudios Peruanos, Instituto de Estudios Sociales y Culturales, Pensar Universidad Javeriana, Universidad Andina Simón Bolívar sede Ecuador. Disponible en: http://www. ram-wan.net/restrepo/documentos/sin_garantias.pdf

Santa Cruz, L. \& Pineda, J. (2009). Cartilla Etnoeducativa 3. Aprender Haciendo. Plantas medicinales del Valle del Chota. Quito: Fondo Documental Afro-Andino, Fundación Centro Ecuatoriano de Hipoterapia y Terapias Alternativas, Programa de Desarrollo Cultural-Centro Cultural del Banco Interamericano de Desarrollo.

Tadeo, R. (1998). Movimiento Negro en Quito. En Savoia, R. \& Gomez, J. (eds.). (1999). El Negro en la Historia del Ecuador: Esclavitud en las Regiones Andina y Amazónica (pp.71-81). Quito: Centro Cultural Afroecuatoriano.

Vera, R. (2015). Dinámicas de la Negritud y Africanidad. Construcciones de la Afrodescendencia en Ecuador. Quito: Abya Yala.

Walsh, C., Abad, E. \& García, J. (2011). Fondo Documental Afro Andino. Video. Disponible en: https://vimeo.com/29752890

Walsh, C. \& García, J. (2002). El pensar del emergente movimiento afro ecuatoriano - Reflexiones desde un proceso. En Mato, D. (ed.). Estudios y otras prácticas intelectuales latinoamericanas en cultura y 
poder (pp. 317-327). Caracas: CLACSO, CEAP, FACES, Universidad Central de Venezuela.

(2017). Pensar sembrando/sembrar pensando con el Abuelo Zenón. Quito: Editorial Abya Yala, Universidad Andina Simón Bolívar, Fondo Afro-Andino. 